\title{
Oncological Diseases and the Use of Bisphosphonates: A Cross- sectional Study in Bulgaria and the Plovdiv Region
}

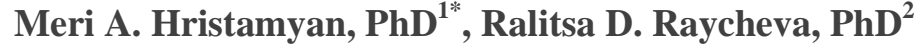 \\ ${ }^{I}$ Department of Epidemiology and Disaster Medicine, Faculty of Public Health, Medical University - Plovdiv, \\ Bulgaria \\ ${ }^{2}$ Department of Social Medicine and Public Health, Faculty of Public Health, Medical University - Plovdiv, \\ Bulgaria
}

*Corresponding Author: Meri A. Hristamyan, PhD, Department of Epidemiology and Disaster Medicine, Faculty of Public Health, Medical University of Plovdiv, Bulgaria, Email: mary_hr@abv.bg

\begin{abstract}
Introduction: Bisphosphonates (BPs) are some of the most commonly used drugs for treating oncology patients with multiple myeloma or bone metastases. In recent years, cases of bisphosphonate-associated osteonecrosis of the jaws (BAONJ) have been increasingly reported in oncology patients on intravenous BPs.
\end{abstract}

Objective: To study the patients with oncological diseases in Bulgaria and in the Plovdiv region and the application of intravenous BPs in patients with malignancies in the Plovdiv region.

Material and Methods: A cross-sectional study was conducted, using as a primary source of information the official publications of the Bulgarian National Cancer Registry (NCR) from 2012 to 2016. Additional information was obtained from hospitals' pharmacy wards located in Plovdiv region, where BP therapy was administrated during the same 5-year period. Data processing and analysis were accomplished using SPSS statistical software (SPSS for Windows, version 24, Armonk, NY: IBM Corp). A p-value <0.05 was considered statistically significant. Time series analysis was applied to study the annual data, obtained from NCR.

Results: In Bulgaria and in Plovdiv, the time series analysis demonstrated a positive trend for the total number of cancer cases, with a significantly higher proportion of women (Bulgaria $(z=103.6, p<0.05)$, Plovdiv $(z=45.9, p<0.05))$. However, for the period, in the newly registered cancer cases we observed higher proportion of men (Bulgaria $(z=10.6, p<0.05)$, Plovdiv $(z=4.7, p<0.05)$ ). The most frequent localization of malignant formations are: skin, mammary gland, female reproductive organs, gastrointestinal tract, and respiratory tract. In Plovdiv, on average, $2.3 \%$ of oncology patients received BPs, with a higher proportion of women $(52 \%, n=402 ; z=1.6, p=0.117)$. Zoledronic acid is the most commonly used BP.

Conclusion: The increasing trend of oncology patients potentially expands the treatment with BPs with possible subsequent development of BAONJ.

Keywords: cancer, oncology, trends, bisphosphonates, osteonecrosis, jaw

\section{INTRODUCTION}

The distribution of oncological diseases has a serios impact on the healthcare system. In addition to the direct invasive treatment of the malignant process, a large proportion of patients are receiving therapy with various types of drugs, one of which are the Bisphosphonates (BPs). They bind to the hydroxyapatite in the bone and inhibit osteoclast-mediated bone resorption [1]. In clinical practice, BPs have been used for several decades to treat multiple myeloma, osteolytic bone metastases, osteoporosis, Paget disease, fibrous dysplasia, hypercalcemia of tumor origin, etc. [2-4]. In recent years, reports of Bisphosphonateassociated osteonecrosis of the jaw (BAONJ) have been increasingly reported in patients treated with BPs. These are patients diagnosed with various oncological diseases: breast cancer, prostate cancer, lung cancer, and multiple myeloma, on intravenous BPs treatment. Although, in the current clinical practice an informed conscent is required, patients are still not familiar with the risk of BAONJ as a serious adverse event of the treatment. Moreover, there 
is not an explicit line of action considering: (1) consultation with a dental specialist for risk assessment; (2) potential need for dental examination before starting the treatment; (3) follow-up and timely treatment during the BPs administration period. This is an extremely complex and multifactorial process requiring monitoring and an individual approach to each patient, and efforts should be directed primarily towards the prevention of BAONJ both before and after initiation of BP therapy.

The aim of this research is to study the patients with oncological diseases in Bulgaria and in the Plovdiv region and the application of intravenous BPs in patients with malignancies in the Plovdiv region.

\section{MATERIALS AND METHODS}

A cross-sectional study was conducted, using as a primary source of information the official publications of the Bulgarian National Cancer Registry (NCR) from 2012 to 2016 (5-year period). The variables studied were: age and gender of patients with neoplasms and newly discovered neoplasms. Additional information was obtained from hospitals' pharmacy wards located in Plovdiv region, where BP therapy was administrated during the same 5-year period. The variables included were: age, gender, type of BP, number I.V. administrations. Continuous variables were expressed as mean \pm standard deviation (SD), or by median $\left(25^{\text {th }}, 75^{\text {th }}\right.$ percentiles), based on normality of data. Difference between averages (medians) was proved by applying two-sample t-test (Mann-Whitney U test), based on the data distribution. Categorical variables were expressed as counts or percentages. Difference between two proportions was analysed by z-test. Data processing and analysis were accomplished using SPSS statistical software (SPSS for Windows, version 24, Armonk, NY: IBM Corp). A p-value $<0.05$ was considered statistically significant. Time series analysis was applied to study the annual data, obtained from NCR.

\section{ReSUlts}

In Bulgaria, for the period 2012-2016, an average of 279421 neoplasms per year have been registered, with an increasing trend (Figure 1). A significantly higher proportion of women was found $(\mathrm{z}=103.6, \mathrm{p}<0.05)(60 \%, \mathrm{n}=167950)$.

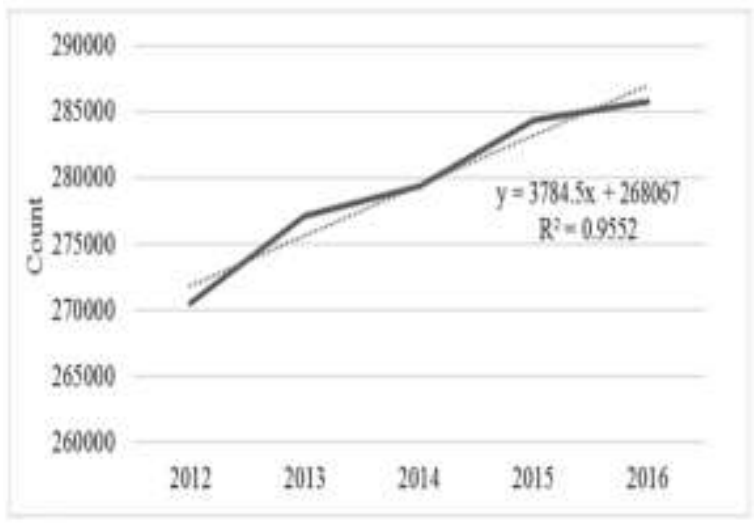

Figure1. Time series analysis and trend of all registered oncological diseases (n) in Bulgaria for a 5-year period

An average of 31474 (11\%) newly registered neoplasms per year has been registered, with a decreasing tendency in the number of cases (Figure 2). On average, the number of newly registered females for the period was 14794 (47\%), whereas the males were 16680 (53\%), with the proportion of men being statistically significant higher higher $(\mathrm{z}=10.6, \mathrm{p}<0.05)$.

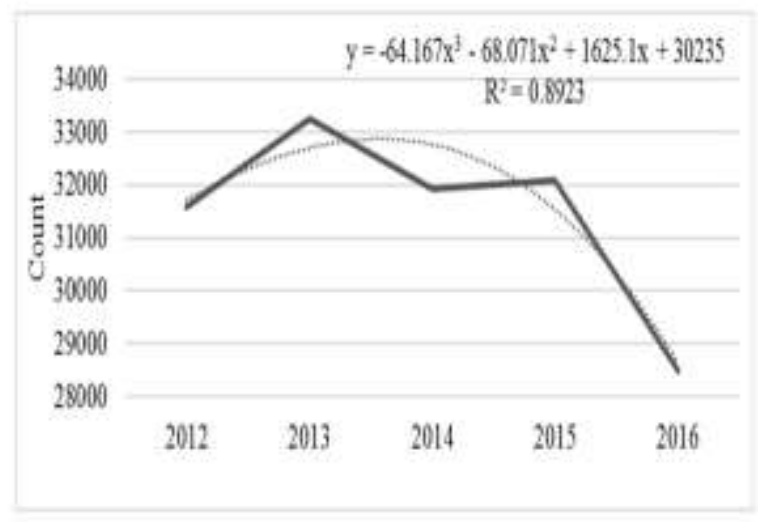

Figure2. Time series analysis and trend of newly registered oncological diseases (n) in Bulgaria for a 5-year period

In the region of Plovdiv, for the period, an average of 33240 (12\% of the average total reported in Bulgaria) neoplasms was registered per year, with a tendency for cases to increase in number (Figure 3). A significantly higher proportion of women $(63 \%, \mathrm{n}=20$ 949) was found $(\mathrm{z}=45.9$, $\mathrm{p}<0.05)$. 


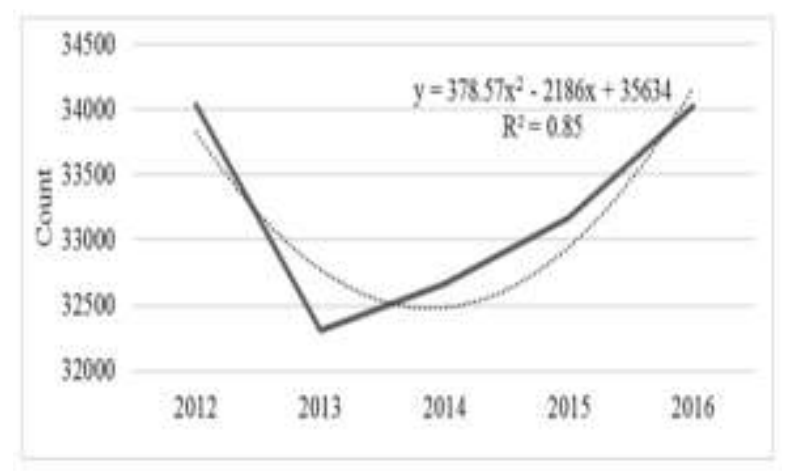

Figure3. Time series analysis and trend of all registered oncological diseases in Plovdiv region for a 5-year period

Newly registered cases in the region are an average of 3399 (10\% of average total reported for Plovdiv region), with a decreasing tendency of the number of cases (Figure 4). On average, the newly registered males were 1819 (54\%) and the females were 1580 (46\%), with an increase in the number of men, a decrease in the number of women, and a significantly higher proportion of men $(\mathrm{z}=4.7, \mathrm{p}<0.05)$.

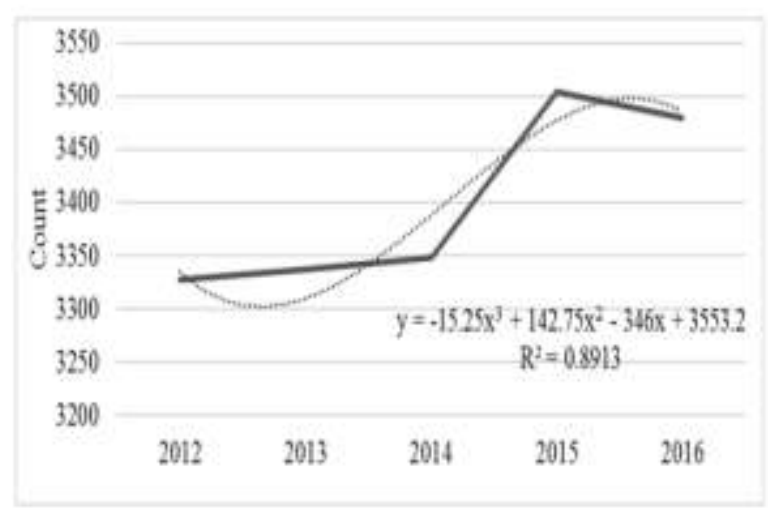

Figure4. Time series analysis and trend of newly registered oncological diseases in Plovdiv region for a 5-year period

In Bulgaria, and in the Plovdiv region, the averagely most common localizations of malignancy for the 5-year period are: skin (63 $816(15 \%)$ / 9106 (18\%)), mammary gland (50 $549(12 \%) / 5927(12 \%))$, female reproductive organs (82 $604(19 \%) / 7779(15 \%))$, gastrointestinal tract $(81090(19 \%) / 9029$ $(18 \%))$, and respiratory tract $(30005(7 \%) / 4$ $245(8 \%))$. There was also an increase in breast cancer and prostate cancer cases. These types of cancer are frequently linked to the development of bone metastases and the need of subsequent BP treatment.

For the period, in the Plovdiv region, an average of $766(2.3 \%)$ of cancer patients received BPs (Table 1), with a higher proportion of women $(52 \%, \mathrm{n}=402 ; \mathrm{z}=1.6, \mathrm{p}=0.117)$ and a median age of 66 yrs. (58 yrs., 73 yrs.).

Table1. Distribution of oncology patients from Plovdiv, receiving intravenous BPs by year for the period $2012-2016$

\begin{tabular}{|c|c|c|c|}
\hline Year & $\begin{array}{c}\text { Number of cancer } \\
\text { patients }\end{array}$ & \multicolumn{2}{|c|}{$\begin{array}{c}\text { Cancer patients, } \\
\text { receiving I.V. BP }\end{array}$} \\
\cline { 3 - 4 } & & n & \% \\
\hline $\mathbf{2 0 1 2}$ & 34031 & 705 & 2.07 \\
\hline $\mathbf{2 0 1 3}$ & 32307 & 738 & 2.28 \\
\hline $\mathbf{2 0 1 4}$ & 32666 & 893 & 2.73 \\
\hline $\mathbf{2 0 1 5}$ & 33173 & 732 & 2.21 \\
\hline $\mathbf{2 0 1 6}$ & 34025 & 763 & 2.24 \\
\hline
\end{tabular}

I.V. = intravenous, $B P=$ Bisphosphonates

Zoledronic acid (ZA) was the BP administered in $3801(99 \%)$ of cases for the overall 5-year period. BPs were mostly used in patient with breast cancer $(13 \%, \mathrm{n}=99)$, onco-hematological diseases $(19 \%, \mathrm{n}=150)$, prostate $(5 \%, \mathrm{n}=43)$ and lung cancer $(4 \%, \mathrm{n}=29)$ (averages for the period). There was a decline in the median number of applications of BPs from an average of 5 (2012-2014) to 3 per year in 2015 and 2016, with women receiving more infusions than men (Man-Whitney U, p<0.0001).

\section{DISCUSSION}

BPs are effective in the treatment of diseases with high bone resorption. The largest group of patients receiving BP therapy are those with oncological diseases. The increasing number of patients with malignancies results in more frequent use of BPs. Thus, in recent years, substantial number of patients had been diagnosed with BAONJ, which, according to some authors, is due to the significantly higher total doses and duration of intravenous therapy with BPs $[1,5]$.

Regarding the incidence of neoplasms, in 2012 Bulgaria occupies the 43rd place in the world [6] with a total of 270492 registered patients. Globally, in 2012, there are 14 million new cases of cancer. The number of new cases is expected to increase to 22 million over the next two decades. More than $60 \%$ of new oncology cases worldwide are seen in Africa, Asia and Central and South America [7]. The global trend of increasing number of patients with cancer is also noticeable in Bulgaria. 
In the US, approximately $39.6 \%$ of men and women will be diagnosed with a malignancy at some point in their lives (based on data from 2010-2012), with 1685210 new cases of cancer [8]. Europe accounts for only one-eighth of the world's population, but there are about a quarter of all cases of cancer with about 3.7 million new patients per year [9]. In 2012, there were about 3.45 million new cases of neoplasms in the European Union, with the number of newly registered men being higher than that of women [10]. In Bulgaria, and in the Plovdiv region, for the 5-year period, we have seen the same gender distribution of newly registered neoplasms.

Globally, in 2012, more than 4 out of 10 new cases of neoplasms are localized in the lungs, mammary glands, colorectal area, or prostate. These 4 types of cancer account for $52 \%$ of all newly registered oncological diseases in the UK in 2014 [11].

As for the frequency of prescription, more than 2.5 million patients worldwide have been treated with BPs [12]. Almost 2 million people receive this treatment as part of cancer therapy [13]. Nowadays the numbers are constantly increasing.

The percentage of women on BP therapy in our study is higher. This trend can be explained by the fact that breast cancer is the most common type of cancer, which may require potential therapy with these drugs. In Germany, BF was the therapy administrated to $9.6 \%$ of the overall patients with breast cancer [14].

We found that the most common type of BP used on cancer patients is Zoledronic acid (ZA). $\mathrm{ZA}$ is the most effective agent from the BP group in terms of reducing skeletal involvement in multiple myeloma, as well as a wide range of solid tumors affecting the bones by $30-50 \%$ [15]. However, ZA is considered to have the highest risk of possible BP complications and has the highest potency measured [16]. This type of BP causes most of the cases of BAONJ $[5,16,17,17,19,20,21,22]$. In patients with breast cancer in Germany, ZA is also the most commonly used BP for the prevention of bone metastases [14]. In Texas (USA) 2/3 of patients with breast cancer receive ZA [23].

The median age of patients receiving BPs in our study coincides with the results reported in studies from five European countries (France,
Germany, Italy, Spain, UK). The mean age of the patients in each group of malignancies (solid tumors - ST and oncohematological diseases OHD) is close (CT: 67.7 yrs., OHD: 67.5 yrs.). From patients with ST, the youngest has German origin (62.6 yrs.) and the oldest registered in Italy (70.3 yrs.). The mean age of patients with OHD is similar in different countries and ranges from 64.3 yrs. to $68.3 \mathrm{yrs}$. [24].

In line with other studies, our results detected that the most common types of malignancies in patients receiving BP therapy in the Plovdiv region are breast cancer, prostate cancer, lung cancer and multiple myeloma [24,25,26,27].

In the last two years of our study, the median number of applications of BPs start to reduce in association with initiated changes in the clinical practice: BPs are not administered every $3 / 4$ weeks as initially recommended, but every 3 months $[20,28,29]$ or even every 6 months [28].

Optimized dosing frequencies of bisphosphonates administration has resulted in less reported severe adverse events [16]. According to the American National AntiNeoplasm Network, there have been no BAONJ cases in bone loss prevention studies with ZA administrated every 6 months [30].

\section{CONClusions}

The results of the study show an increase in patients with oncologic diseases, especially the types that metastasize to the bones and need subsequent bisphosphonate treatment, and therefore a potential increase of BAONJ is expected. Our efforts should be directed to improve the communication between healthcare practitioners and patients to facilitate the management of BAONJ. Further research is required to identify the preventive measures and flexible treatment protocols, adapted to the individual patient, giving priority to patients' quality of life.

\section{ACKNOWLEDGMENTS}

The paper was supported by the Ministry of Education and Science, Republic of Bulgaria (National program "Young scientists and postdoctoral students").

\section{CONFLICTS OF INTEREST}

There are no conflicts of interest to disclose. 


\section{REFERENCES}

[1] Lam DK, Sándor GK, Holmes HI, Evans AW, Clokie CM. A review of bisphosphonateassociated osteonecrosis of the jaws and its management. J Can Dent Assoc. 2007 Jun;73(5):417-22.

[2] Conte P, Guarneri V. Safety of intravenous and oral bisphosphonates and compliance with dosing regimens. Oncologist. 2004;9 Suppl 4:28-37.

[3] Dannemann C, Zwahlen R, Grätz KW. Clinical experiences with bisphopsphonate induced osteochemonecrosis of the jaws. Swiss Med Wkly. 2006 Aug 5;136(31-32):504-9.

[4] Chapurlat RD, Hugueny P, Delmas PD, Meunier PJ. Treatment of fibrous dysplasia of bone with intravenous pamidronate: long-term effectiveness and evaluation of predictors of response to treatment. Bone. 2004 Jul;35(1):235-42.

[5] Campisi G, Fedele S, Fusco V, Pizzo G, Di Fede O, Bedogni A. Epidemiology, clinical manifestations, risk reduction and treatment strategies of jaw osteonecrosis in cancer patients exposed to antiresorptive agents. Future Oncol. 2014 Feb;10(2):257-75.

[6] Global cancer data by country. Exploring which countries have the highest cancer rates. http://www.wcrf.org/int/cancer-factsfigures/data-cancer-frequency-country (Accessed on September 21, 2020).

[7] WHO:Cancer Fact Sheets. http://www.who.int/mediacentre/factsheets/fs29 7/en/ (Accessed on 12 September 2020).

[8] National cancer institute. Cancer Statistics. https://www.cancer.gov/about-

cancer/understanding/statistics (Accessed on April 21, 2020).

[9] WHO Europe: Cancer - Data and statistics. http://www.euro.who.int/en/healthtopics/noncommunicable-diseases/cancer/dataand-statistics (Accessed on September 21, 2020).

[10] Ferlay J, Steliarova-Foucher E, Lortet-Tieulent J, Rosso S, Coebergh JW, Comber H, Forman D, Bray F. Cancer incidence and mortality patterns in Europe: estimates for 40 countries in 2012. Eur J Cancer. 2013 Apr;49(6):1374-403.

[11] Cancer research UK:Worldwide cancer incidence statistics. http://www.cancerresearchuk.org/healthprofessional/cancer-statistics/worldwidecancer/incidence (Accessed on September 21, 2020).

[12] Tarasoff P, Csermak K. Avascular necrosis of the jaws: risk factor in metastatic cancer patients J Oral Maxillofac Surg. 2003; 61: 1238-1239.
[13] Pechalova P, Poriazova E, Pavlov N, Bakardjiev A. Bisphosphonate - Related Osteonecrosis of the Jaws - Diagnosis and Management. Textbook of Advanced Oral and Maxillofacial Surgery, edited by Mohammad HoseinKalantarMotamedi, 2013, Chapter 10, 279-299

[14] Fick EM, Katalinic A, Waldmann A. The Frequency of and Risk Factors for the Use of Bisphosphonates in the Adjuvant Setting of Primary Breast Cancer in Germany. Cancer Res Treat. 2015 Oct;47(4):747-56.

[15] Coleman $\mathrm{R}$ The use of bisphosphonates in cancer treatment, Ann N Y Acad Sci. 2011 Feb;1218:3-14. doi: 10.1111/j.17496632.2010.05766.x (Accessed on September 21, 2020).

[16] Marx RE. Risk factors for antiresorptive drugrelated osteonecrosis of the jaw. Antiresorptive Drug-related Osteonecrosis of the Jaw (ARONJ) - a Guide to Research Kenneth E Fleisher, RistoKontio, Sven Otto.2016 ; 39-44.

[17] American Association of Oral and Maxillofacial Surgeons. Medication-Related Osteonecrosis of the Jaw - 2014 Update. http://www.aaoms.org/docs/position_papers/mr onj_position_paper.pdf?pdf=MRONJ PositionPaper (Accessed on September 21, 2020).

[18] Bamias A, Kastritis E, Bamia C, Moulopoulos LA, Melakopoulos I, Bozas G, Koutsoukou V, Gika D, Anagnostopoulos A, Papadimitriou C, Terpos E, Dimopoulos MA. Osteonecrosis of the jaw in cancer after treatment with bisphosphonates: incidence and risk factors. J Clin Oncol. 2005 Dec 1;23(34):8580-7.

[19] Dannemann C, Grätz KW, Riener MO, Zwahlen RA. Jaw osteonecrosis related to bisphosphonate therapy: a severe secondary disorder. Bone. 2007 Apr;40(4):828-34.

[20] Corso A, Varettoni M, Zappasodi P, Klersy C, Mangiacavalli S, Pica G, Lazzarino M. A different schedule of zoledronic acid can reduce the risk of the osteonecrosis of the jaw in patients with multiple myeloma. Leukemia. 2007 Jul;21(7):1545-8.

[21] Durie BG, Katz M, Crowley J. Osteonecrosis of the jaw and bisphosphonates. N Engl J Med. 2005 Jul 7;353(1):99-102; discussion 99-102.

[22] Berenson J.R. Stopeck A.T. Medication-related osteonecrosis of the jaw in patients with cancer. (C)2015

UpToDate. https://www.uptodate.com/contents/medication -related-osteonecrosis-of-the-jaw-in-patientswith-cancer (Accessed on September 28, 2020).

[23] Giordano SH, Fang S, Duan Z, Kuo YF, Hortobagyi GN, Goodwin JS. Use of intravenous bisphosphonates in older women with breast cancer. Oncologist. 2008 May; 13(5):494-502. 
[24] Lebret T, Casas A, Cavo M, Woll PJ, Deleplace C, Kennedy C, Schoen P, Jackisch C. The use of bisphosphonates in the management of bone involvement from solid tumours and haematological malignancies - a European survey. Eur J Cancer Care (Engl). 2017 Jul;26(4):e12490.

[25] Luon D. Bisphosphonates in Cancer:Bad to the Bone. http://sites.utexas.edu/pharmacotherapyrounds/files/2015/09/luon12-19-14.pdf 12/19/2014 (Accessed on September 21, 2020).

[26] Van den Wyngaert T, Huizing MT, Fossion E, Vermorken JB. Bisphosphonates in oncology: rising stars or fallen heroes. Oncologist. 2009 Feb;14(2):181-91.

[27] Oster G, Lamerato L, Glass AG, Richert-Boe KE, Lopez A, Chung K, Richhariya A, Dodge T, Wolff GG, Balakumaran A, Edelsberg J. Use of intravenous bisphosphonates in patients with breast, lung, or prostate cancer and metastases to bone: a 15-year study in two large US health systems. Support Care Cancer. 2014 May;22(5):1363-73.

[28] Coleman R, Body JJ, Aapro M, Hadji P, Herrstedt J; ESMO Guidelines Working Group. Bone health in cancer patients: ESMO Clinical Practice Guidelines. Ann Oncol. 2014 Sep;25Suppl 3:iii124-37.

[29] Niraula S, Templeton AJ, Vera-Badillo F, Dodd A, Nugent Z, Joshua AM, Tannock IF. Duration of suppression of bone turnover following treatment with zoledronic acid in men with metastatic castration-resistant prostate cancer. Future Sci OA. 2017 Oct 20;4(1):FSO253.

[30] Gralow JR, Biermann JS, Farooki A, Fornier MN, Gagel RF, Kumar RN, Shapiro CL, Shields A, Smith MR, Srinivas S, Van Poznak CH. NCCN Task Force Report: Bone Health in Cancer Care. J Natl ComprCancNetw. 2009 Jun;7Suppl 3(Suppl 3):S1-32; quiz S33-5.

Citation: Meri A. Hristamyan, Ralitsa D. Raycheva. "Oncological Diseases and the Use of Bisphosphonates: A Cross-sectional Study in Bulgaria and the Plovdiv Region”. ARC Journal of Dental Science. 2021; 6(1):3-8. DOI: https://doi.org/10.20431/2456-0030.0601002.

Copyright: (C) 2021 Authors. This is an open-access article distributed under the terms of the Creative Commons Attribution License, which permits unrestricted use, distribution, and reproduction in any medium, provided the original author and source are credited. 